Article

\title{
Variation in the Reported Management of Canine Prolapsed Nictitans Gland and Feline Herpetic Keratitis
}

\author{
Constance N. White ${ }^{1}$, Gareth Jones ${ }^{2}$, Sarah Baker ${ }^{3}$, Rachel S. Dean ${ }^{4}$ \\ and Marnie L. Brennan ${ }^{4, *}$ (1) \\ 1 Fremont Veterinary Clinic, Portland, OR 97213, USA; doctornev2000@yahoo.com \\ 2 Park Veterinary Group, 162 Dominion Rd, Glenfield LE3 8JA, UK; Gareth.Jones@parkvetgroup.com \\ 3 3f2 24 Bread St, Edinburgh EH3 9AF, UK; s-j1390@hotmail.co.uk \\ 4 Centre for Evidence-Based Veterinary Medicine, School of Veterinary Medicine and Science, \\ The University of Nottingham, Sutton Bonington Campus, Loughborough LE12 5RD, UK; \\ Rachel.Dean@nottingham.ac.uk \\ * Correspondence: marnie.brennan@nottingham.ac.uk; Tel.: +44-115-951-6577
}

Received: 23 March 2018; Accepted: 23 May 2018; Published: 1 June 2018

\begin{abstract}
Treatment variation in medicine may be driven by evidence gaps, clinician factors, and patient preferences. Although well-documented in human medicine, variation in clinical management is relatively unexplored in veterinary practice. Clinical vignette questionnaires were administered to a cross section of general practitioners (GPs) and veterinarians with postgraduate training in ophthalmology (PGs) to survey recommended management of canine prolapsed nictitans gland ("cherry eye", PNG) and feline herpesvirus (FHV-1) keratitis. The majority of veterinarians (96.2\%) suggested surgical replacement of cherry eye, with a pocketing technique being the most frequently nominated procedure. GPs were more likely to suggest gland excision in the event of surgical failure, while PGs more frequently nominated techniques incorporating a periosteal anchor for salvage repair. Most respondents managed FHV-1 keratitis with topical antibiotics $(76.4 \%)$, with a minority suggesting topical antivirals (32.2\%). GPs favoured topical acyclovir whilst PGs more frequently recommended topical trifluorothymidine. A significantly larger proportion of PGs nominated systemic famciclovir and lysine supplement for FHV-1 keratitis. This survey revealed moderate treatment variation for these conditions, both between and within practitioner groups. Additional research is needed to assess the reasons for this variation, particularly for conditions in which high quality evidence is scant.
\end{abstract}

Keywords: cherry eye; nictitans prolapse; third eyelid gland; feline herpes keratitis; treatment variation; clinical vignette

\section{Introduction}

Prolapsed nictitans gland ("cherry eye", PNG) of dogs is a condition commonly encountered by veterinarians, particularly in predisposed breeds [1,2]. Multiple surgical procedures for correction have been described in the veterinary literature which require varying surgical proficiency and equipment [3] (pp. 963-964). Gland excision has been discouraged due to recognition of the gland's contribution to tear production and a study showing higher risk of keratoconjunctivitis sicca (KCS) in dogs after excision [3] (p. 963) [4] (p. 80) [5] (p. 163) [6] (p. 206) [7] . Apart from this fiat, we are unaware of any directive guidance for management of cherry eye, with surgical technique currently considered a matter of personal preference [3] (p. 964). Similarly, feline herpesvirus (FHV-1) may result in morbid and relapsing corneal and conjunctival disease in cats. In contrast to cherry eye, definitive diagnosis of 
FHV-1 keratitis is challenging even with molecular testing [8,9]. No veterinary drugs are labelled for herpetic keratitis and there is little clinical research to guide treatment decisions in naturally occurring disease $[8,9]$.

In human medicine, greater treatment variation may occur for conditions which lack high level evidence or guidelines [10]. Vignette-based questionnaires have been used to assess treatment patterns and variation in human clinical practice, as well to identify areas of clinical uncertainty [11-13]. Use of open, rather than closed, questions in vignettes may provide better insight into actual current practice [14]. We are unaware of any published literature documenting treatment patterns of these two ocular disorders in first opinion or ophthalmology practice. Ophthalmology practice patients may differ from primary care in a number of ways: cases may vary in severity, as well as available owner resources and practice capabilities. Heterogeneous management strategies may highlight resource and evidence gaps encountered by veterinarians in the treatment of these conditions and identify areas of priority for research in veterinary ophthalmology. The aim of this study was to survey veterinarians about their management of PNG in dogs and herpetic keratitis in cats. Additionally, we sought to explore variation in treatment amongst all veterinarians and between veterinarians in general practice (GPs) and those with additional ophthalmology training (PGs), with reference to published evidence regarding the treatment of these conditions.

\section{Materials and Methods}

\subsection{Sampling and Data Collection}

The target population was all members of the veterinary profession in the UK treating small animal patients. The sampling frames were a convenience sample of veterinarians on a mailing list for the Centre for Evidence-based Veterinary Medicine (CEVM) and attendees at the British Association of Veterinary Ophthalmologists (BrAVO) Winter Conference (2012).

Questionnaires (Supplementary Materials) were constructed consisting of open and closed-end questions across five sections. These sections covered the diagnostic tools used for ophthalmological cases, the sources of information accessed by vets, and factors considered in clinical decision-making, as well as questions relating to respondent demographics. The additional two sections presented two clinical vignettes - the first based on a Lhasa Apso with a PNG and the second a domestic shorthaired cat with dendritic herpetic keratitis. After each vignette, veterinarians were asked what treatments, additional investigations, long term management and recheck advice they would give for each case. Design of the vignettes was based on "textbook" cases to minimize diagnostic confusion while the associated questions were derived from a similar survey undertaken [15]. Questionnaires were pre-tested by eight individuals not engaged in the veterinary profession, and piloted by ten veterinarians engaged in academic and private practice.

The online questionnaire was constructed and administered through cloud-based survey software (Survey Monkey Inc., San Mateo, CA, USA) using an email list of interested respondents collected from a previous survey conducted by the Centre for Evidence-based Veterinary Medicine [16]. Online respondents were encouraged to fill out the questionnaire by being entered into a prize draw for a $£ 80$ gift voucher in exchange for their participation; respondents were anonymized prior to analysis. The online survey was initiated in October 2012 and closed in November 2012. A first reminder was sent 10 days after the initial email, followed by a final reminder two days before survey close. Paper questionnaires with identical vignette, treatment, diagnostic, and ancillary management questions were distributed to the attendees of the British Association of Veterinary Ophthalmologists Winter conference and were collected back by two authors (MB, SB) at the end of the day (3 November 2012).

\subsection{Data Management and Analysis}

Returned online surveys were downloaded to a spreadsheet (Microsoft Excel) whilst paper survey responses were manually entered into the same spreadsheet. The data from every 10th questionnaire 
manually entered was checked for any transcription errors. Minimal errors were encountered. Data relating to proposed treatments and diagnostic investigations were extracted from open ended responses by one coder (CNW) and categorically classified as to generic drug name or category, surgical or procedural interventions, diagnostic tests, and other patient assessments. Data related to long term recommendations were extracted by one coder $(\mathrm{CNW})$ and classified as categorical data regarding prognosis, salvage treatment options, chronicity, and owner communications. Level of training in veterinary ophthalmology was assessed by questionnaire and de-anonymized email addresses after data extraction and coding. Data relating to the sources of information accessed by vets and factors considered in clinical decision making are not reported here but will appear in an additional manuscript.

Statistical analysis was performed with a commercially available statistical package (Stata IC13). Continuous data (age, years since graduation, recheck intervals) were assessed for normality by the Shapiro-Wilk normality test and were subsequently analyzed by using Mann-Whitney U tests. Chi-square tests were used to compare categorical data between groups except when expected cell counts were $\leq 5$, where the more conservative Fisher's exact test was used. Correction for multiple comparisons was done using the Dunn-Bonferroni method [17]. Not all respondents answered all questions; proportions are calculated using the total numbers of respondents completing each question unless otherwise indicated. Statistical significance was set at the 0.05 level. Significant $p$ values are reported in text when not included in tables.

Ethical approval for the study was received from the ethics committee at the School of Veterinary Medicine and Science at the University of Nottingham.

\section{Results}

\subsection{Response Rate}

Of 1412 successful email invitations, 269 (18.9\%) online surveys were submitted. Of 101 questionnaires distributed to British Veterinary Ophthalmologist Association (BrAVO) conference attendees, 57 (56.4\%) completed questionnaires were collected. Of the total number of eligible responses received from the online cohort, 259 were engaged in general practice (from here on known as "GPs") while 10 had or were training for a postgraduate certificate in veterinary ophthalmology. Those 10 were combined with $50 \mathrm{BrAVO}$ attendees to form a cohort with postgraduate training in veterinary ophthalmology (from here on known as postgraduate training group, "PGs"). Remaining BrAVO attendees who had not enrolled in or completed a postgraduate ophthalmology training course $(n=7)$ were combined with the GP online cohort. Not all 326 respondents answered all questions within the questionnaire (Table 1).

Table 1. Demographic and vignette question response rates.

\begin{tabular}{lcccccc}
\hline Question & Overall $\mathbf{n}$ & Overall \% & GP $\mathbf{n}$ & GP $\%$ & PG $\mathbf{~}$ & PG $\%$ \\
\hline Survey & 326 & & 266 & & 60 & \\
Age & 231 & 70.9 & 171 & 64.3 & 60 & 100 \\
Gender & 231 & 70.9 & 171 & 64.3 & 60 & 100 \\
Graduation year & 230 & 70.6 & 170 & 63.9 & 60 & 100 \\
Initial prolapse treatment & 261 & 80.0 & 201 & 75.6 & 60 & 100 \\
Prolapse surgical failure treatment & 184 & 56.4 & 129 & 48.5 & 55 & 91.7 \\
Nictitans additional recommendations & 182 & 55.8 & 128 & 48.1 & 54 & 90.0 \\
FHV-1 initial treatment & 233 & 71.5 & 174 & 65.4 & 59 & 98.3 \\
FHV-1 relapse & 214 & 65.6 & 160 & 60.2 & 54 & 90.0 \\
FHV-1 additional recommendations & 233 & 71.5 & 174 & 65.4 & 59 & 98.3 \\
\hline
\end{tabular}

\subsection{Respondent Characteristics}

Fifty eight percent of respondents reporting gender were female. Overall median age of respondents was 40 years (Table 2). Median age and gender distribution of PGs as compared to GPs was 
not significantly different, although female PGs were marginally more likely to be older than female GPs. When de-anonymized by email address subsequent to analysis, a majority of PG respondents were engaged partly $(15 \%)$ or exclusively $(75 \%)$ in referral practice. Credentials were verified for the 60 PG respondents: RCVS Specialist (DVOphthal, DipECVO, FANZCVS, $n=9$ ), Certificate of Veterinary Ophthalmology (CertVOphthal, $\mathrm{n}=38$ ), Post Graduate Certificate in Ophthalmology (GPCert or PgCert, $n=8)$, GPCert/PgCert Ophthalmology candidates $(n=2)$, unnamed certificate in ophthalmology $(n=1)$, post-graduate research or training in veterinary ophthalmology $(n=2)$.

Table 2. Demographic characteristics of GP and PG respondents.

\begin{tabular}{|c|c|c|c|c|c|c|c|}
\hline & Overall n & Overall & GP n & GP & PG n & PG & $p$ Value \\
\hline Male & 96 & $41.6 \%$ & 66 & $38.6 \%$ & 30 & $50.0 \%$ & 0.123 \\
\hline No answer given & 95 & & 95 & & 0 & & \\
\hline \multicolumn{8}{|l|}{ Age } \\
\hline Median age (all) & $230 *$ & 40 & 171 & 39 years & 59 & 40 years & 0.2151 \\
\hline No answer age and/or gender & 97 & & 96 & & 1 & & \\
\hline \multicolumn{8}{|l|}{ Year of qualification } \\
\hline Median year qualified (all) & 230 & 1996.5 & 170 & 1997 & 60 & 1995 & 0.1227 \\
\hline Median year qualified (male) & 95 & 1993 & 65 & 1992 & 30 & 1994.5 & 0.9553 \\
\hline Median year qualified (female) & 134 & 1999 & 104 & 2000 & 30 & 1996.5 & 0.0541 \\
\hline
\end{tabular}

* One individual who answered age question provided a range rather than discrete number thus could not be included in summary data analysis.

\subsection{Prolapsed Nictitans Gland}

The majority of both groups recommended surgical replacement of a prolapsed gland (Table 3). PGs were more likely to specify use of a pocket procedure while GPs were less likely to specify type of surgical procedure. Periosteal anchoring was mentioned by a small number of respondents as an alternative to pocketing but was rarely recommended as the sole initial technique. A small but significantly larger proportion of GPs considered gland excision as sole or alternative therapy for the initial episode of prolapse. A greater proportion of GPs recommended a trial of medical therapy prior to surgical intervention, although the difference did not reach statistical significance after correction for multiple comparisons. The most common therapies recommended for medical therapy were topical steroids $(n=32)$, manual reduction $(n=24)$, topical antibiotic $(n=16)$, and topical lubricant $(n=9)$.

Table 3. Canine PNG treatments recommended by GP and PG groups responding to a vignette questionnaire.

\begin{tabular}{lccccccc}
\hline Treatments & Overall $\mathbf{n}$ & Overall $\%$ & GP $\mathbf{n}$ & GP $\%$ & PG $\mathbf{n}$ & PG $\%$ & $p$ Value \\
\hline Total respondents & 261 & & 201 & & 60 & & \\
All replacement & 251 & 96.2 & 191 & 95.0 & 60 & 100 & 0.078 \\
surgery & 125 & 47.9 & 75 & 37.3 & 50 & 83.3 & $* \mathbf{0 . 0 0 0}$ \\
$\quad$ Pocket & 8 & 3.1 & 5 & 2.5 & 3 & 5.0 & $\ddagger 0.390$ \\
$\quad$ Pocket or anchor & 6 & 2.3 & 6 & 3.0 & 0 & 0 & $\ddagger 0.342$ \\
$\quad$ Periosteal anchor & 112 & 42.9 & 105 & 52.2 & 7 & 11.7 & $* \mathbf{0 . 0 0 0}$ \\
$\quad$ Unspecified surgery & 24 & 9.2 & 24 & 11.9 & 0 & 0 & $* \mathbf{0 . 0 0 5}$ \\
Excision option & 9 & 3.4 & 9 & 4.5 & 0 & 0 & $\ddagger 0.124$ \\
Excision only & 59 & 22.6 & 52 & 25.9 & 7 & 11.7 & 0.021 \\
Medical trial & & & & & & &
\end{tabular}

* Significant with Bonferroni corrected $p<0.05$; bolded $p$ values are significant after correction for multiple comparison testing; ${ }^{\ddagger}$ Fisher's exact test. 
Revision surgery suggestions for surgical failure were more varied and proportions for each procedure differed from first recommendations (Table 4). GPs were significantly more likely to consider gland excision than were PGs. PGs more frequently recommended use of periosteal anchoring (either alone or in combination with pocketing) as compared to their initial treatment suggestions (Figure 1). Of those who initially chose pocketing, $45 \%$ proposed the same technique for revision.

Table 4. Canine PNG surgical failure treatments recommended by GP and PG groups responding to a vignette questionnaire.

\begin{tabular}{lccccccc}
\hline Treatments & Overall $\mathbf{n}$ & Overall \% & GP $\mathbf{n}$ & GP $\%$ & PG $\mathbf{n}$ & PG $\%$ & $p$ Value \\
\hline Total respondents & 184 & & 129 & & 55 & & \\
All replacement surgery & 166 & 90.2 & 112 & 86.8 & 54 & 98.2 & $* \mathbf{0 . 0 1 8}$ \\
$\quad$ Pocket & 51 & 27.7 & 31 & 24.0 & 20 & 36.4 & 0.087 \\
$\quad$ Periosteal anchor & 20 & 10.9 & 11 & 8.5 & 9 & 16.4 & 0.118 \\
Pocket or anchor & 4 & 2.2 & 0 & 0 & 4 & 7.3 & $*$. 0.007 \\
Pocket + / anchor & 5 & 2.7 & 0 & 0 & 5 & 9.1 & $* \mathbf{0 . 0 0 1}$ \\
Pocket + anchor & 7 & 3.8 & 2 & 1.6 & 5 & 9.1 & 0.014 \\
All techniques with anchoring & 36 & 19.6 & 13 & 10.1 & 23 & 41.8 & $* \mathbf{0 . 0 0 0}$ \\
Perilimbal pocket (Prémont) & 1 & 0.5 & 0 & 0 & 1 & 1.8 & $\ddagger 0.299$ \\
Unspecified surgery & 78 & 42.4 & 68 & 52.7 & 10 & 18.2 & $* \mathbf{0 . 0 0 0}$ \\
Excision option & 37 & 20.1 & 36 & 27.9 & 1 & 1.8 & $* \mathbf{0 . 0 0 0}$ \\
Excision only & 10 & 5.4 & 10 & 7.8 & 0 & 0 & $\ddagger 0.034$ \\
\hline
\end{tabular}

* Significant with Bonferroni corrected $p<0$ 05; bolded $p$ values are significant after correction for multiple comparison testing. ¥ Fisher’s exact test.

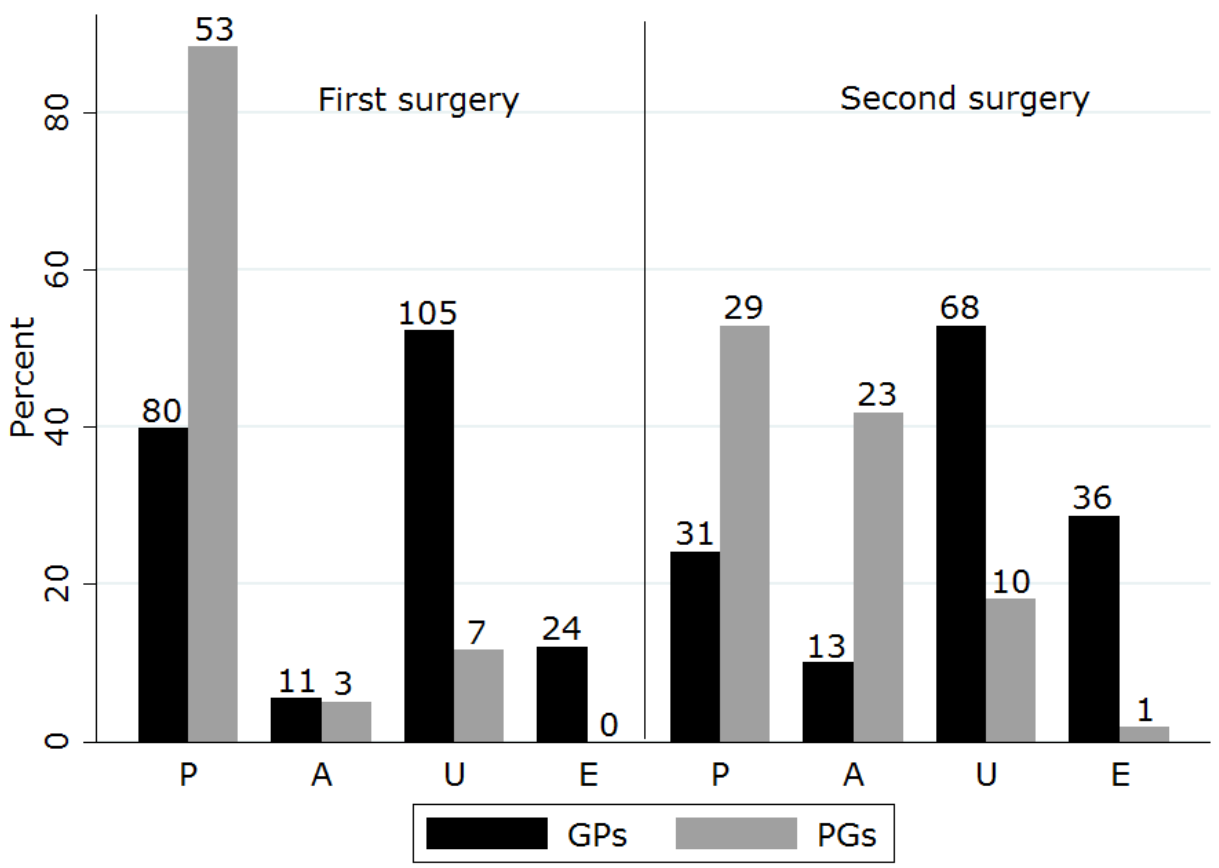

Figure 1. Surgical options nominated for treatment of prolapsed nictitans gland on first occurrence and for recurrence ( $\mathrm{P}$, pocket suggestion; A, anchoring suggestion; E, excision; $\mathrm{U}$, unspecified replacement surgery suggestion).

A significant number of respondents suggested discussing the possibility of surgical failure with owners with no difference between groups (Table 5). However, PGs were significantly more likely to note the risk of prolapse in the contralateral eye and marginally more likely to state they would discuss possible keratoconjunctivitis sicca (KCS) sequelae in the operated eye. 
Table 5. Additional PNG management recommendations by GP and PG groups responding to a vignette questionnaire.

\begin{tabular}{lccccccc}
\hline Recommendation & Overall $\mathbf{n}$ & Overall \% & GP $\mathbf{n}$ & GP \% & PG n & PG \% & $p$ Value \\
\hline Total respondents & 182 & & 128 & & 54 & & \\
Discuss risk of prolapse in contralateral eye & 69 & 37.9 & 40 & 31.3 & 29 & 53.7 & $* 0.004$ \\
Warn owner of surgical failure & 58 & 31.9 & 44 & 34.4 & 14 & 25.9 & 0.264 \\
Discuss monitoring for KCS & 50 & 27.5 & 29 & 22.7 & 21 & 38.9 & 0.025 \\
$\begin{array}{l}\text { Recommend prophylactic surgery } \\
\text { contralateral eye }\end{array}$ & 7 & 3.8 & 3 & 2.3 & 4 & 7.4 & $\ddagger 0.198$ \\
\hline
\end{tabular}

* Significant with Bonferroni corrected $p<0.05$. ₹ Fisher's exact test.

Nearly a quarter ( $n=47,23.4 \%$ ) of GPs offered referral for initial and/or revision replacement surgery; of those, 23 indicated that they did not have proficiency in surgical replacement. Six GPs who had recommended periosteal anchoring for initial or revision surgery specified referral for that procedure. Four of 20 individuals who indicated unavailable treatments indicated that they had no ability to refer to a veterinary ophthalmologist.

\subsection{FHV-1 Keratitis}

When presented with the case of feline dendritic keratitis, the majority of both groups recommended the use of a topical antibiotic (Table 6). Topical antiviral agents and topical lubricants were recommended by a third of respondents with no significant difference between groups. There were few recommendations for topical NSAIDs or autologous serum. A variety of topical antibiotics were nominated (Figure 2). Fusidic acid was most frequently suggested, followed by chloramphenicol and tetracyclines, with no significant differences found between groups for any agent. Similarly, a number of topical antiviral drugs were suggested (Figure 3). A significantly higher proportion of PGs recommended topical trifluorothymidine than did GPs (chi square $p=0.000$ ).

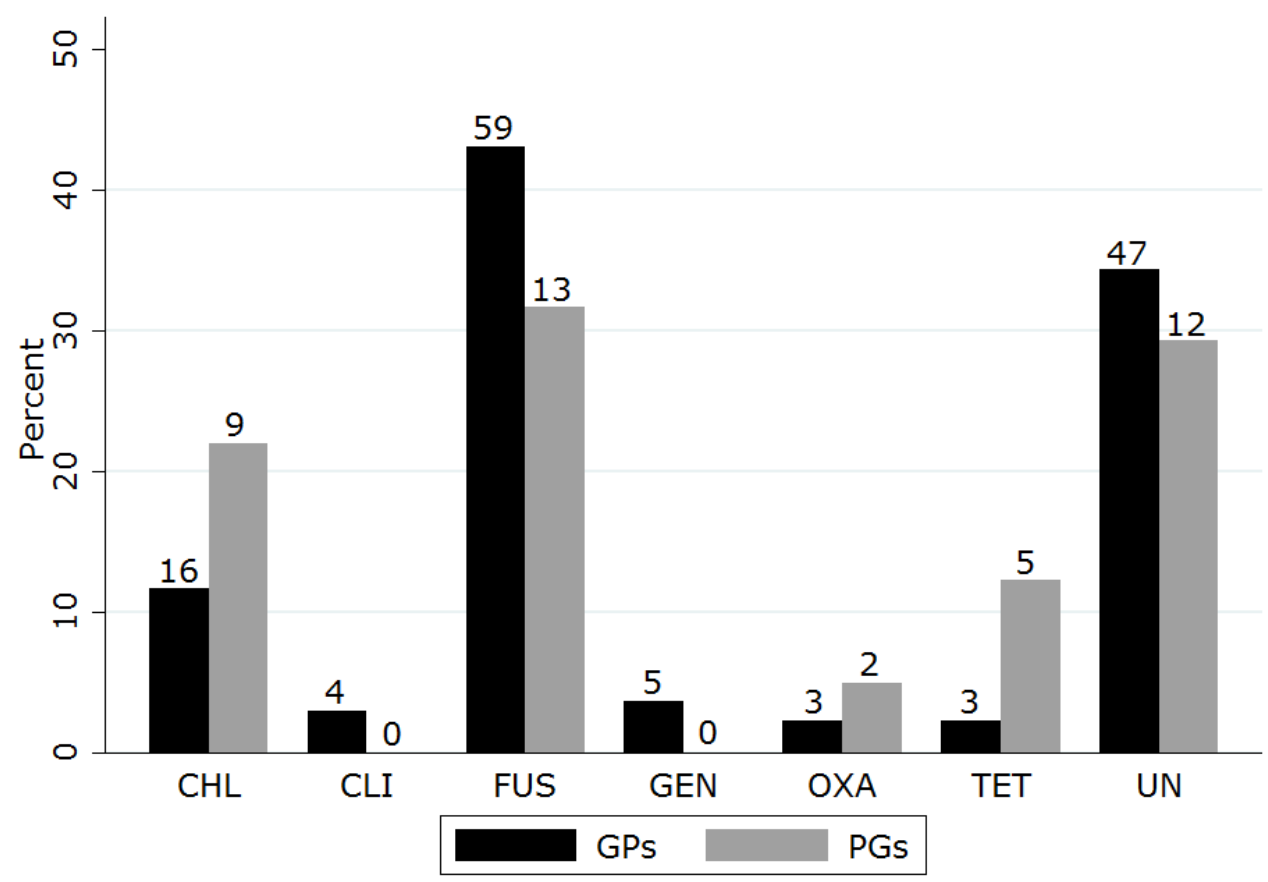

Figure 2. Topical antibiotic choices for FHV-1 keratitis selected by UK general practitioners and postgraduate groups who suggested topical antibiotic therapy in a questionnaire-based survey (CHL, chloramphenicol; CLI, clindamycin; FUS, fusidic acid; GEN, gentamycin; OXA, oxacillin; TET, tetracyclines; UN, unspecified; numbers indicate number of respondents suggesting treatment). 
Table 6. FHV-1 keratitis topical treatments recommended by GP and PG groups responding to a vignette questionnaire.

\begin{tabular}{llllllll}
\hline Treatments & Overall $\mathbf{n}$ & Overall \% & GP n & GP \% & PG n & PG \% & $p$ Value \\
\hline Total respondents & 233 & & 174 & & 59 & & \\
Antibiotic & 178 & 76.4 & 137 & 78.7 & 41 & 69.5 & 0.148 \\
Antiviral & 75 & 32.2 & 58 & 33.3 & 17 & 28.8 & 0.521 \\
Lubricant & 77 & 33.0 & 52 & 29.9 & 25 & 42.4 & 0.078 \\
NSAID ${ }^{1}$ & 8 & 3.4 & 8 & 4.6 & 0 & 0.0 & $\ddagger 0.207$ \\
Autologous serum & 9 & 3.9 & 8 & 4.6 & 1 & 1.7 & $\ddagger 0.455$ \\
\hline
\end{tabular}

${ }^{\ddagger}$ Fisher's exact test. ${ }^{1}$ nonsteroidal anti-inflammatory.

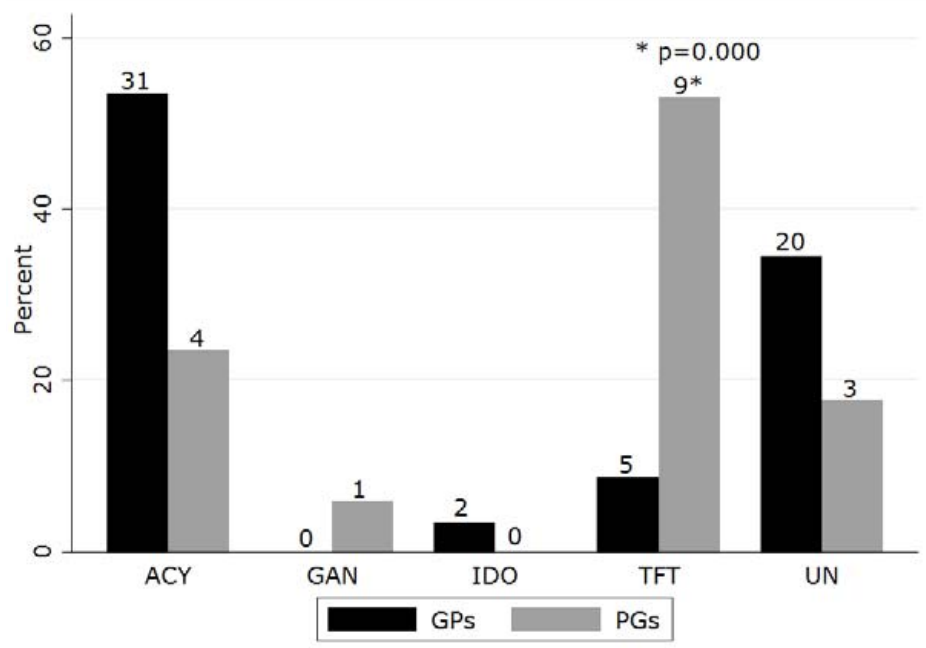

Figure 3. Topical antiviral choices for FHV-1 keratitis selected by UK general practitioners and postgraduate groups who suggested topical antiviral therapy in a questionnaire-based survey (ACY, acyclovir; GAN, ganciclovir; IDO, idoxuridine; TFT, trifluorothymidine; UN, unspecified; numbers indicate number of respondents suggesting treatment).

Suggested systemic therapies for FHV-1 keratitis were more varied between the two groups. PGs were significantly more likely to nominate a systemic antiviral (famciclovir when specified) and lysine supplement (Table 7). Slightly more than a third of all respondents suggested a systemic nonsteroidal anti-inflammatory (NSAID), often citing analgesia, with a smaller number of respondents recommending interferon or systemic antibiotics (amoxicillin-clavulanate $n=7$, doxycycline $n=12$, clindamycin $n=1$, unspecified $n=9$ ).

Table 7. FHV-1 keratitis systemic therapies recommended by GP and PG groups responding to a vignette questionnaire.

\begin{tabular}{lccccccc}
\hline Treatments & Overall $\mathbf{n}$ & Overall \% & GP n & GP $\%$ & PG n & PG \% & $p$ Value \\
\hline Total respondents & 233 & & 174 & & 59 & & \\
NSAID & 80 & 34.3 & 59 & 33.9 & 21 & 35.6 & 0.814 \\
$\quad$ Meloxicam & 41 & 17.6 & 34 & 19.5 & 7 & 11.9 & \\
Carprofen & 1 & 0.4 & 1 & 0.6 & 0 & 0 & \\
Unspecified & 38 & 16.3 & 24 & 13.8 & 14 & 23.7 & \\
Lysine & 75 & 32.2 & 46 & 26.4 & 29 & 49.2 & $* 0.001$ \\
Antiviral & 68 & 29.2 & 30 & 17.2 & 38 & 64.4 & $* 0.000$ \\
$\quad$ Famciclovir & 65 & 27.9 & 27 & 15.5 & 38 & 64.4 & \\
Unspecified & 3 & 1.3 & 3 & 1.7 & 0 & 0 & \\
Interferon & 33 & 14.2 & 24 & 13.8 & 9 & 15.2 & 0.781 \\
Antibiotic & 29 & 12.4 & 23 & 13.2 & 6 & 10.2 & 0.540 \\
\hline
\end{tabular}

* Significant with Bonferroni corrected $p<0.05$. 
Additional recommendations for treatment were varied. More than $5 \%$ of respondents recommended discussing recurrence, environmental stress, and issues of contagion (Figure 4). GPs were more likely to recommend regular vaccination (chi square $p=0.006$ ) whilst PGs were more likely to discuss stress avoidance (chi square $p=0.001$ ). Few respondents recommended diagnostic testing for FHV-1; when specified, polymerase chain reaction (PCR) and/or virus isolation was frequently recommended. In addition to these top five recommendations, 32 additional suggestions were offered by $<5 \%$ of respondents which covered surgery (debridement, keratotomy, third eyelid, and conjunctival flaps), atropine, FeLV/FIV testing, vaccination of contacts, homeopathy, contact lens, steroids, cyclosporine, deworming, vitamin $\mathrm{E}$, lecithin, and recommendations to avoid vaccination. All recommendations aside from the top five were suggested only by the GP group with the single exception of one PG who suggested deworming.

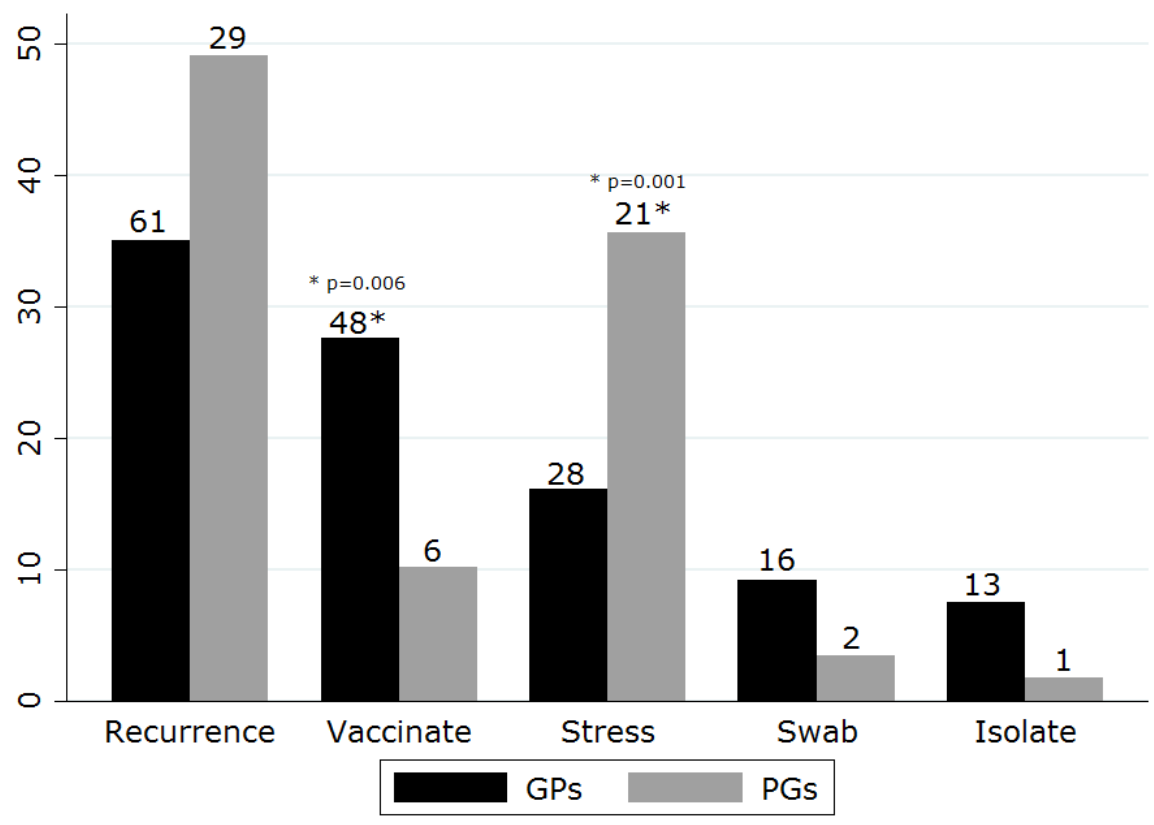

Figure 4. Additional recommendations for FHV-1 keratitis as nominated by general practitioners and postgraduate groups based in the UK in a questionnaire-based survey (Recurrence, discussed likelihood of recurrence; Vaccinate, discussed need for regular vaccination; Stress, discussed stress/environmental triggers; Swab diagnostics, recommended submission of ophthalmic swab for diagnostic testing; Isolate, discussed contagion to other cats and/or recommended isolation). Numbers indicate number of respondents making suggestion.

Recommendations for relapse did not differ substantially from initial treatment suggestions. The majority of respondents suggested repeating their initial treatment advice $(71.3 \%$ GPs, $81.5 \%$ PGs). A small number of respondents who had not previously suggested surgery $(n=20)$, antiviral therapy $(n=15)$, lysine supplement $(n=7)$, interferon $(n=9)$, or systemic antibiotic therapy $(n=3)$ did so for relapsed cases. No new recommendations for topical antibiotics were made, although a few respondents $(\mathrm{n}=3)$ recommended changing to a different antibiotic. Suggested surgical procedures were keratectomy, debridement, third eyelid flaps, conjunctival flaps, and enucleation.

A number of respondents indicated there were herpesvirus treatments which were unavailable to them (25.5\% GPs, $16.1 \%$ PGs). More than half of these (55.5\%) suggested that access to antiviral drugs was limited; although most respondents did not name specific agents, those cited were trifluorothymidine $(n=4)$, famciclovir $(n=3)$, cidofovir $(n=1)$, and idoxyuridine $(n=1)$. 


\section{Discussion}

There appeared to be variation in treatment recommendations elicited by clinical vignettes of PNG and FHV-1 keratitis, which could potentially impact on the consistency of care given to animals affected by these conditions. Prior work has demonstrated treatment variation in cardiac, endocrine, and ocular diseases of companion animals [15,18-20]. This study provides additional evidence for such variation: although suggestions for initial treatment of PNG were generally consistent amongst all veterinarians, approaches to surgical failure varied more between GPs and PGs. Moreover, a wider range of treatments were suggested for FHV-1 keratitis, with larger discordance between GPs and PGs in the use of systemic agents.

Most respondents suggested surgical replacement of PNG, although more GPs trialed medical therapy prior to surgical intervention. Most chose a pocket procedure for initial repair (when the technique was specified). Although a variety of techniques for gland replacement have been published [7,21-28], there is limited data for comparative efficacy on surgical and lacrimal outcomes, particularly for breeds thought to be at higher risk for recurrence or for development of KCS. Morgan's pocket technique is considered technically less challenging than some other procedures and is frequently covered in ophthalmology surgical texts [3-6,29], factors which may have driven popularity amongst respondents. Our finding that periosteal anchoring was suggested more frequently by PGs for revision surgery suggests that it may be favored in patients more prone to recurrence, a view reinforced by some authors $[28,30]$ and a recent study showing decreased recurrence in English Bulldogs when pocketing was augmented with a periosteal tack [22]. It is noteworthy that some of the GPs in our survey suggested referral specifically for periosteal anchoring, suggesting less comfort with the surgical technique in that group.

A significantly greater number of GPs considered gland excision in the case of first surgery failure. Gland excision, though commonly recommended in the past [31], is currently discouraged due to published evidence of concomitant reduction of tear production [32-35]. Although a retrospective study associated excision with subsequent development of KCS [7], a number of respondents who suggested excision as a treatment option stated that they had never encountered this complication. KCS risk varies by sex, breed, and age [36-38]. It is likely that excision-related KCS may similarly vary and that willingness to excise may reflect experience with patient mix that is not fully captured by the published literature. Alternatively, since prolonged prolapse may also be associated with higher KCS risk [7], respondents may have suggested excision to serve owner cosmetic and financial preferences, rather than lacrimal function. Finally, since onset of KCS often occurs years after excision (mean 3.06 years, median 4.5 years [7]), it is possible that clinicians who did not report this complication may have been biased by shorter follow-up times.

Currently and at the time of this survey, there are no approved veterinary pharmaceutical products for the treatment of FHV-1 keratitis. Suggested therapeutics have generally been derived from in vitro efficacy studies, experimental infection, and case series reports $[8,39]$. Topical antibiotics (recommended by the majority of all respondents) are used in both human and feline keratitis primarily for the prevention and treatment of secondary infection $[8,9,40,41]$. Although the difference did not reach statistical significance, more PG respondents recommended use of a lubricant. We speculate that lubricants may have been suggested due to tear film abnormalities documented in cats experimentally infected with FHV-1 [42], as well as to improve ocular comfort [30].

Although a similar proportion of PGs and GPs recommended a topical antiviral, product choice was disparate between groups, with a larger proportion of PGs suggesting trifluorothymidine. This may be due, in part, to limited availability of some topical preparations in the UK; trifluorothymidine must be obtained through the single national ophthalmic compounding pharmacy in the UK. However, aside from a controlled trial of cidofovir [43], topical antiviral efficacy has generally been deduced from in vitro and uncontrolled observational data [39]; perhaps as a consequence, disparate product recommendations are common in veterinary references [5] (pp. 396-399) [30] (p. 250) [44] (p. 470). 
General practitioners and PGs diverged more dramatically in their systemic FHV-1 therapy recommendations, notably in the greater popularity of famciclovir and lysine amongst PGs. At the time of this survey, preliminary experimental safety and efficacy data for famciclovir in feline FHV-1 had been published, along with a small case series [45-47]. However, famciclovir therapy had not yet been included in contemporary texts or was discouraged due to safety concerns [48] (p. 145) [30] (p. 72) [44] (p. 470). Lysine recommendations also varied between authors at the time of this survey. The European Cat Advisory Board included lysine as a recommended antiviral agent in their 2009 guidelines [9] whilst a contemporary evidence-based management guide suggested that lysine was futile at best and could potentially worsen disease and viral shedding [8]. Two recent systematic reviews summarizing evidence available at the time of this survey have also suggested no evidence for lysine in prevention or treatment of FHV-1 or prevention of human herpes simplex labialis $[49,50]$. However, lysine is still considered potentially beneficial by some veterinary ophthalmologists and virologists [39,51]. Our survey was not designed to elicit reasons for variation but we speculate that the lower number of lysine suggestions from GPs might reflect differences in information sources, evidence appraisal, or product availability between the two groups.

Although stress avoidance and recognition of FHV-1 chronicity emerged as consensus themes amongst respondents, vaccine recommendations varied by practitioner group. Current vaccine guidelines vary in suggested FHV-1 vaccine intervals due to non-sterilizing immunity and uncertainty regarding duration of immunity [9,52]; some suggest that FHV-1 may recrudesce in latent carriers following modified live FHV-1 vaccination $[51,53]$. Thus, practitioner recommendations may vary depending on information source. Finally, we were struck by numerous and varied additional recommendations for management of FHV-1 keratitis. It has been suggested that treatment proliferation occurs for chronic disease in which little is known and empirical therapy forms the basis for practice [54] (p. 63).

Treatment variation in human medicine is greater in areas with larger evidence gaps and for conditions which lack clinical guidelines [10]. Additionally, physician social networks have been shown to drive regional variation in prostate cancer and coronary artery disease care in the United States $[55,56]$. In veterinary medicine, few high quality clinical trials are available, constraining information sources to lower levels of evidence [57]. In this environment, information sources, social networks, and client preferences may drive care more substantially and further work in identifying the sources of veterinary treatment variation is needed. While guidelines may help reduce heterogeneity in clinical decision making, they are ideally formulated using best available evidence alongside inclusion of all stakeholders into the guideline process. Our results, combined with the accompanying survey of current evidence, suggest that there is need for both guidelines for companion animal ocular disease and additional research to establish optimal treatment for these conditions. In the low resource setting of veterinary medicine, electronic medical records could be leveraged to collect multicentre cohort data, create patient registries, and serve as the basis of pragmatic clinical trials.

Supplementary Materials: The following are available online at http:/ / www.mdpi.com/2306-7381/5/2/54/s1, Questionnaire 1: Online questionnaire, Questionnaire 2: British Association of Veterinary Ophthalmologists Winter Meeting questionnaire.

Author Contributions: M.L.B., G.J. and R.S.D. conceived and designed the experiments; M.L.B. and S.B. performed the experiments; S.B. and C.N.W. analyzed the data; C.N.W. and M.L.B. wrote the paper. All authors contributed to and checked the manuscript before submission.

Acknowledgments: The authors wish to thank the veterinarians who participated in the survey. This work was initiated and sponsored as part of an undergraduate veterinary research project at the University of Nottingham (S.B.) and extended in partial fulfillment of the requirements for a Master of Public Health degree (C.N.W., University of Southern California).

Conflicts of Interest: The authors declare no conflict of interest. 


\section{References}

1. ACVO Genetics Committee. Ocular Disorders Presumed to Be Inherited in Purebred Dogs; American College of Veterinary Ophthalmologists: Meridian, ID, USA, 1996; ISBN 978-0-9635163-1-2.

2. O'Neill, D.G.; Church, D.B.; McGreevy, P.D.; Thomson, P.C.; Brodbelt, D.C. Prevalence of disorders recorded in dogs attending primary-care veterinary practices in England. PLoS ONE 2014, 9. [CrossRef] [PubMed]

3. Hendrix, D.V.H. Veterinary Ophthalmology, 5th ed.; Gelatt, K.N., Gilger, B.C., Eds.; Wiley: Hoboken, NJ, USA, 2013; ISBN 978-0-470-96040-0.

4. Crispin, S.M. Notes on Veterinary Ophthalmology; John Wiley \& Sons: Hoboken, NJ, USA, 2009; ISBN 1-4051-4544-7.

5. Maggs, D.J.; Miller, P.; Ofri, R. Slatter's Fundamentals of Veterinary Ophthalmology, 5th ed.; Elsevier Health Sciences: New York, NY, USA, 2012; ISBN 1-4377-2368-3.

6. Martin, C.L. Ophthalmic Disease in Veterinary Medicine; Manson Publishing Ltd.: London, UK, 2005; ISBN 1-84076-016-8.

7. Morgan, R.V.; Duddy, J.M.; McClurg, K. Prolapse of the gland of the third eyelid in dogs: A retrospective study of 89 cases (1980 to 1990). J. Am. Anim. Hosp. Assoc. 1993, 29, 56-60.

8. Gould, D. Feline herpesvirus-1: Ocular manifestations, diagnosis and treatment options. J. Feline Med. Surg. 2011, 13, 333-346. [CrossRef] [PubMed]

9. Thiry, E.; Addie, D.; Belák, S.; Boucraut-Baralon, C.; Egberink, H.; Frymus, T.; Gruffydd-Jones, T.; Hartmann, K.; Hosie, M.J.; Lloret, A.; et al. Feline herpesvirus infection. ABCD guidelines on prevention and management. J. Feline Med. Surg. 2009, 11, 547-555. [CrossRef] [PubMed]

10. Skinner, J. Causes and consequences of regional variations in health care. Handb. Health Econ. 2011, 2, 45-93.

11. Bruce, K.K.; Merenstein, D.J.; Narvaez, M.V.; Neufeld, S.K.; Paulus, M.J.; Tan, T.P.; Braunstein, J.R.; Pfaff, A.C.; Huang, C.C.; Friedland, R.B. Lack of Agreement on Distal Radius Fracture Treatment. J. Am. Board Fam. Med. 2016, 29, 218-225. [CrossRef] [PubMed]

12. Paulus, M.C.; Braunstein, J.; Merenstein, D.; Neufeld, S.; Narvaez, M.; Friedland, R.; Bruce, K.; Pfaff, A. Variability in orthopedic surgeon treatment preferences for nondisplaced scaphoid fractures: A cross-sectional survey. J. Orthop. 2016, 13, 337-342. [CrossRef] [PubMed]

13. Van Esch, A.A.; Ali, U.A.; van Goor, H.; Bruno, M.J.; Drenth, J.P. A wide variation in diagnostic and therapeutic strategies in chronic pancreatitis: A Dutch national survey. JOP 2012, 13, 394-401. [CrossRef] [PubMed]

14. Pham, T.; Roy, C.; Mariette, X.; Lioté, F.; Durieux, P.; Ravaud, P. Effect of response format for clinical vignettes on reporting quality of physician practice. BMC Health Serv. Res. 2009, 9, 128. [CrossRef] [PubMed]

15. Davies, T.; Everitt, S.; Cobb, M. Variation in the management of congestive cardiac failure in dogs. Vet. Rec. 2015, 176, 435. [CrossRef] [PubMed]

16. Nielsen, T.D.; Dean, R.S.; Robinson, N.J.; Massey, A.; Brennan, M.L. Survey of the UK veterinary profession: common species and conditions nominated by veterinarians in practice. Vet. Rec. 2014, 174, 324. [CrossRef] [PubMed]

17. Pagano, M.; Gauvreau, K.; Pagano, M. Principles of Biostatistics, 2nd ed.; Pacific Grove: Duxbury, CA, USA, 2000.

18. Sinclair, J.; Dunning, M.; Dean, R.; Cobb, M. Canine diabetes mellitus; monitoring and survival in first opinion practice. In BSAVA Congress 2014, Birmingham, UK, 3-6 April 2014. Scientific Proceedings Veterinary Programme; British Small Animal Veterinary Association: Gloucester, UK, 2014; p. 593.

19. White, C.N.; Downes, M.J.; Jones, G.; Wigfall, C.; Dean, R.S.; Brennan, M.L. Use of clinical vignette questionnaires to investigate the variation in management of keratoconjunctivitis sicca and acute glaucoma in dogs. Vet. Rec. 2018, 182, 21. [CrossRef] [PubMed]

20. Rishniw, M.; Pion, P.D. Is treatment of feline hypertrophic cardiomyopathy based in science or faith? A survey of cardiologists and a literature search. J. Feline Med. Surg. 2011, 13, 487-497. [CrossRef] [PubMed]

21. Kaswan, R.L.; Martin, C.L. Surgical correction of third eyelid [gland] prolapse in dogs. J. Am. Vet. Med. Assoc. 1985, 186, 83. [PubMed]

22. Multari, D.; Perazzi, A.; Contiero, B.; de Mattia, G.; Iacopetti, I. Pocket technique or pocket technique combined with modified orbital rim anchorage for the replacement of a prolapsed gland of the third eyelid in dogs: 353 Dogs. Vet. Ophthalmol. 2016, 19, 214-219. [CrossRef] [PubMed] 
23. Plummer, C.E.; Kllberg, M.E.; Gelatt, K.N.; Gelatt, J.P.; Barrie, K.P.; Brooks, D.E. Intranictitans tacking for replacement of prolapsed gland of the third eyelid in dogs. Vet. Ophthalmol. 2008, 11, 228-233. [CrossRef] [PubMed]

24. Prémont, J.E.; Monclin, S.; Farnir, F.; Grauwels, M. Perilimbal pocket technique for surgical repositioning of prolapsed nictitans gland in dogs. Vet. Rec. 2012, 171, 247. [CrossRef] [PubMed]

25. Sapienza, J.S.; Mayordomo, A.; Beyer, A.M. Suture anchor placement technique around the insertion of the ventral rectus muscle for the replacement of the prolapsed gland of the third eyelid in dogs: 100 Dogs. Vet. Ophthalmol. 2014, 17, 81-86. [CrossRef] [PubMed]

26. Twitchell, M.J. Surgical repair of a prolapsed gland of the 3rd eyelid in the dog. Mod. Vet. Pract. 1984, 65, 223. [PubMed]

27. Blogg, J.R. Surgical replacement of a prolapsed gland of the third eyelid ("cherry eye"). A new technique. Aust. Vet. Pract. 1979, 9, 75.

28. Moore, C.P.; Constantinescu, G.M. Surgery of the Adnexa. Vet. Clin. Small Anim. Pract. 1997, 27, 1011-1066. [CrossRef]

29. Gómez, J.B.R. Repairing nictitans gland prolapse in dogs. Vet. Rec. 2012, 171, 244. [CrossRef] [PubMed]

30. Turner, S.M. Small Animal Ophthalmology; Elsevier Health Sciences: New York, NY, USA, 2008; ISBN 0-7020-2872-X.

31. Barnett, K.C. Diseases of the nictitating membrane of the dog. J. Small Anim. Pract. 1978, 19, 101-108. [CrossRef] [PubMed]

32. Dugan, S.J.; Severin, G.A.; Hungerford, L.L.; Whiteley, H.E.; Roberts, S.M. Clinical and histologic evaluation of the prolapsed third eyelid gland in dogs. J. Am. Vet. Med. Assoc. 1992, 201, 1861-1867. [PubMed]

33. Gelatt, K.N.; Peiffer, R.L., Jr.; Erickson, J.L.; Gum, G.G. Evaluation of tear formation in the dog, using a modification of the Schirmer tear test. J. Am. Vet. Med. Assoc. 1975, 166, 368-370. [PubMed]

34. Helper, L.C.; Magrane, W.G.; Koehm, J.; Johnson, R. Surgical induction of keratoconjunctivitis sicca in the dog. J. Am. Vet. Med. Assoc. 1974, 165, 172-174. [PubMed]

35. Saito, A.; Izumisawa, Y.; Yamashita, K.; Kotani, T. The effect of third eyelid gland removal on the ocular surface of dogs. Vet. Ophthalmol. 2001, 4, 13-18. [CrossRef] [PubMed]

36. Barnett, K.C. Keratoconjunctivitis sicca: Sex incidence. J. Small Anim. Pract. 1988, 29, 531-534. [CrossRef]

37. Sanchez, R.F.; Innocent, G.; Mould, J.; Billson, F.M. Canine keratoconjunctivitis sicca: Disease trends in a review of 229 cases. J. Small Anim. Pract. 2007, 48, 211-217. [CrossRef] [PubMed]

38. Sansom, J.; Barnett, K.C. Keratoconjunctivitis sicca in the dog: A review of two hundred cases. J. Small Anim. Pract. 1985, 26, 121-131. [CrossRef]

39. Thomasy, S.M.; Maggs, D.J. A review of antiviral drugs and other compounds with activity against feline herpesvirus type 1. Vet. Ophthalmol. 2016, 19 (Suppl. 1), 119-130. [CrossRef] [PubMed]

40. Shaikh, S.; Ta, C.N. Evaluation and management of herpes zoster ophthalmicus. Am. Fam. Phys. 2002, 66, 1723-1730.

41. Wilhelmus, K.R. Therapeutic interventions for herpes simplex virus epithelial keratitis. Cochrane Database Syst. Rev. 2008. [CrossRef]

42. Lim, C.C.; Reilly, C.M.; Thomasy, S.M.; Kass, P.H.; Maggs, D.J. Effects of feline herpesvirus type 1 on tear film break-up time, Schirmer tear test results, and conjunctival goblet cell density in experimentally infected cats. Am. J. Vet. Res. 2009, 70, 394-403. [CrossRef] [PubMed]

43. Fontenelle, J.P.; Powell, C.C.; Veir, J.K.; Radecki, S.V.; Lappin, M.R. Effect of topical ophthalmic application of cidofovir on experimentally induced primary ocular feline herpesvirus- 1 infection in cats. Am. J. Vet. Res. 2008, 69, 289-293. [CrossRef] [PubMed]

44. Waters, L.; Barnett, K.C. Feline Medicine and Therapeutics; Chandler, E.A., Gaskell, R.M., Gaskell, C.J., Eds.; John Wiley \& Sons: Hoboken, NJ, USA, 2008; ISBN 978-0-470-68045-2.

45. Malik, R.; Lessels, N.S.; Webb, S.; Meek, M.; Graham, P.G.; Vitale, C.; Norris, J.M.; Power, H. Treatment of feline herpesvirus-1 associated disease in cats with famciclovir and related drugs. J. Feline Med. Surg. 2009, 11, 40-48. [CrossRef] [PubMed]

46. Thomasy, S.M.; Maggs, D.J.; Moulin, N.K.; Stanley, S.D. Pharmacokinetics and safety of penciclovir following oral administration of famciclovir to cats. Am. J. Vet. Res. 2007, 68, 1252-1258. [CrossRef] [PubMed] 
47. Thomasy, S.M.; Lim, C.C.; Reilly, C.M.; Kass, P.H.; Lappin, M.R.; Maggs, D.J. Evaluation of orally administered famciclovir in cats experimentally infected with feline herpesvirus type-1. Am. J. Vet. Res. 2011, 72, 85-95. [CrossRef] [PubMed]

48. Maggs, D.J.; Miller, P.E.; Ofri, R.; Slatter, D.H. Slatter's Fundamentals of Veterinary Ophthalmology; Saunders Elsevier: New York, NY, USA, 2008; ISBN 978-0-7216-0561-6.

49. Bol, S.; Bunnik, E.M. Lysine supplementation is not effective for the prevention or treatment of feline herpesvirus 1 infection in cats: A systematic review. BMC Vet. Res. 2015, 11, 284. [CrossRef] [PubMed]

50. Chi, C.-C.; Wang, S.-H.; Delamere, F.M.; Wojnarowska, F.; Peters, M.C.; Kanjirath, P.P. Interventions for prevention of herpes simplex labialis (cold sores on the lips). Cochrane Database Syst. Rev. 2015. [CrossRef] [PubMed]

51. Stiles, J. Ocular manifestations of feline viral diseases. Vet. J. 2014, 201, 166-173. [CrossRef] [PubMed]

52. Sparkes, A.H. Feline vaccination protocols: Is a consensus emerging? SAT Schweiz. Arch. Tierheilkd. 2010, 152, 135-140. [CrossRef] [PubMed]

53. Wennogle, S.A.; Lappin, M.R. Effects of Subcutaneous or Intranasal Vaccine Administration on Clinical Signs in FHV-1-Infected Cats Without Previous Vaccination. 2014 ACVIM Forum Research Abstracts Program. J. Vet. Intern. Med. 2014, 28, 1065.

54. Stokes, W.; Bell, J. Lectures on the Theory and Practice of Physic, 2nd ed.; Barrington, E., Haswell, G.D., Eds.; U.S. National Library of Medicine: Bethesda, MD, USA, 1840.

55. Burke, M.A.; Fournier, G.M.; Prasad, K. Geographic variations in a model of physician treatment choice with social interactions. J. Econ. Behav. Organ. 2010, 73, 418-432. [CrossRef]

56. Pollack, C.E.; Weissman, G.; Bekelman, J.; Liao, K.; Armstrong, K. Physician social networks and variation in prostate cancer treatment in three cities. Health Serv. Res. 2012, 47, 380-403. [CrossRef] [PubMed]

57. Vandeweerd, J.-M.; Kirschvink, N.; Clegg, P.; Vandenput, S.; Gustin, P.; Saegerman, C. Is evidence-based medicine so evident in veterinary research and practice? History, obstacles and perspectives. Vet. J. (Lond. Engl. 1997) 2012, 191, 28-34. [CrossRef] [PubMed]

(C) 2018 by the authors. Licensee MDPI, Basel, Switzerland. This article is an open access article distributed under the terms and conditions of the Creative Commons Attribution (CC BY) license (http:/ / creativecommons.org/licenses/by/4.0/). 